\title{
Einsatzmöglichkeiten von Botulinumtoxin
}

$\mathrm{B}$ otulinumtoxin (BTX) wird von dem anaeroben Bacterium C. botulinum gebildet und gilt als das stärkste biologische Gift. Erste Beschreibungen des durch die Intoxikation hervorgerufenen Krankheitsbildes, des Botulismus, finden sich bereits in der Antike und im Mittelalter.

BTX wirkt an der neuromuskulären Endplatte durch Bindung an SNARE Proteine, wodurch die Freisetzung von Acetylcholin in den synaptischen Spalt verhindert wird. Heute befinden sich zwei der sieben bekannten Serotypen des BTX-Moleküls als Medikament im Handel, BTX-A (Botox ${ }^{\circledR}$, Dysport ${ }^{\circledR}$ und Xeomin $^{\circledR}$ ) und BTX-B (Neurobloc $\left.{ }^{\circledR}\right)$, die für unterschiedliche Indikationen zugelassen sind.

Seit den frühen 80er Jahren weiß man um den medizinischen Nutzen der Substanz. Ursprünglich und erstmals 1977 eingesetzt für die Behandlung des Schielens von dem amerikanischen Augenarzt Dr. Alan Scott in San Francisco, entstanden von Jahr zu Jahr neue Indikationsfelder. BTX gilt heute als Therapie der ersten Wahl bei fokalen Dystonien, wie dem Schiefhals (Torticollis spasmodicus), Erkrankungen wie dem Hemispasmus facialis oder dem Blepharospasmus. Ergänzend zu anderen Therapieverfahren hat BTX inzwischen einen festen Platz in der Therapie der Spastizität, vor allem bei der kindlichen Zerebralparese und bei umschriebenen Formen der Spastik an Hand und Fuß bei Kindern wie Erwachsenen. Viele weitere Indikationsbereiche wurden erschlossen: Das krankhafte Schwitzen (Hyperhidrosis, gustatorisches Schwitzen) gehört dazu, spezielle Schmerzformen, vor allem Kopf- und Rückenschmerzen, lassen sich recht gut behandeln. In der breiten Öffentlichkeit hat BTX auch durch den kosmetischen Einsatz bei Gesichtsfalten Aufsehen erregt. Seltener angewandt, jedoch nicht weniger hilfreich, sind Indikationen im Bereich der Urologie. Nischenindikationen wie Bruxismus oder Myokymie zeigen die Vielfalt der Anwendungsmöglichkeiten.

In den Artikeln dieses Heftes äußern sich anerkannte Experten mit langjähriger Erfahrung über die häufigsten und wichtigsten Anwendungsgebiete. Hierzu zählt vor allem die fokale Dystonie, keine andere Therapie ist hier besser wirksam, und vor allem verträglicher. Nicht zu- letzt bei den technisch schwierig zu behandelnden Aufgaben-spezifischen Dystonien wie dem Schreibkrampf oder sehr umschriebenen Formen der Spastik an der Hand kann die EMG-gesteuerte Injektion sinnvoll sein. Auch durch Ultraschall-Kontrolle kann die Treffsicherheit der Injektion in den Muskel gesteigert werden. Wie viel Sinn macht es, sich dieser Hilfstechniken zu bedienen? Wird dadurch die Wirksamkeit der Methode wirklich besser? Prof. Dr. Ceballos-Baumann berichtet hierüber in einem kritischen Beitrag.

Prof. Dr. Wissel beschreibt zusammen mit Prof. Dr. Naumann das Vorgehen bei Spastizität. Hier sind angemessene, meist höhere Dosierungen erforderlich und die richtige Wahl der Injektionsorte entscheidet über den Behandlungserfolg. Ziel ist dabei nicht nur die Senkung des Tonus, sondern letztlich die Verbesserung der Mobilität, ungewollte Schwächung der Muskulatur muss nach Möglichkeit vermieden werden.

Störungen der autonomen Funktionen wie übermäßiges Schwitzen (Hyperhidrosis) haben in manchen Fällen Krankheitswert, vielfach wird dies auch von den Kostenträgern heute anerkannt. Die BTX-Injektion in die Haut kann hier ohne nennenswerte Nebenwirkungen oder Risiken Abhilfe schaffen. Frau Dr. Sonntag berichtet aus ihrer Erfahrung bei dieser Anwendung. Die Wirkung, die in der Regel nach drei bis fünf Tagen eintritt, hält hier manchmal bei zu einem halben Jahr an.

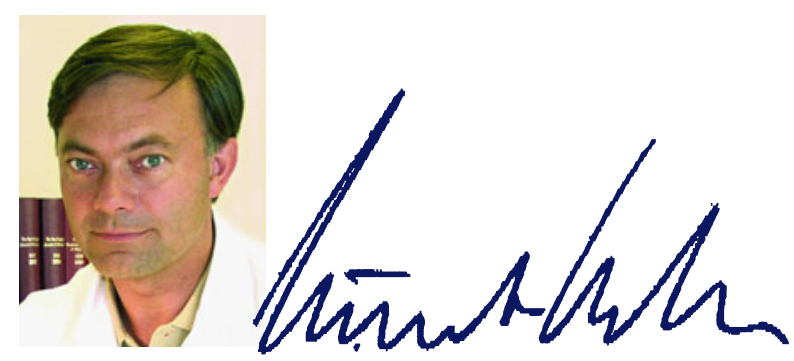

Prof. Dr. Günter Ochs, Ingolstadt 